Article

\title{
Effect of Thermo-Oxidative Ageing on Nano-Morphology of Bitumen
}

\author{
Wengang Zhang ${ }^{1, * \mathbb{C}}$, Ling Zou ${ }^{2}$, Zhirong Jia ${ }^{1, * \mathbb{C}}$, Fang Wang ${ }^{3}$, Ying $\mathrm{Li}^{1}$ and Ping Shi ${ }^{1}$ \\ 1 School of Civil and Architectural Engineering, Shandong University of Technology, Zibo 255049, China \\ 2 CCCC First Highway Consultants Co., Ltd., Xi'an 710065, China \\ 3 School of Physics and Optoelectronic Engineering, Shandong University of Technology, Zibo 255049, China \\ * Correspondence: ziwuzizwg@sdut.edu.cn (W.Z.); jiazhr@126.com (Z.J.); Tel.: +86-05332780964 (W.Z.); \\ +86-05332781800 (Z.J.)
}

Received: 16 May 2019; Accepted: 25 July 2019; Published: 26 July 2019

check for updates

\begin{abstract}
In recent years, the research on bitumen has reached the nanometer level, but there are still some problems in the study of the relationship between the atomic force microscope (AFM) nano-morphology and ageing of bitumen. The purpose of this paper is to find out the effect of thermal oxygen ageing on the nano-morphology of bitumen. Atomic force microscope (AFM) test sample of bitumen was prepared in this paper. Area ratio of bee-like structure, roughness, and maximum amplitude were selected as the nano-morphological parameters of the bitumen. The calculation method of nano-parameters was also proposed. Bitumen with different ageing degrees was prepared by thin film oven test (TFOT). Nano-morphological parameters of bitumen with different ageing degrees were obtained by AFM and analyzed with NanoScope Analysis, and the relationships between nano-morphological parameters and bitumen technical indexes after ageing, such as penetration, ductility, softening point, and viscosity were analyzed. The test results show that the wave crests and wave troughs of the bee-like structure on the surface of the bitumen alternate, while the other areas are relatively flat. The bee-like structure continues to develop as the ageing time prolongs, and the number of bee-like structures decreases, but the volume and the undulation degree increase. With the ageing time prolonging, the nano-parameters of bitumen, such as the area ratio of bee-like structure, roughness, and maximum amplitude, show a trend of increasing gradually, but the increasing rates become smaller and smaller. During the ageing process of bitumen, with the increase of nano-morphological parameters (area ratio of bee-like structure, roughness, and maximum amplitude), penetration at $25^{\circ} \mathrm{C}$ and ductility at $15^{\circ} \mathrm{C}$ of the bitumen decrease, and softening point and viscosity at $60^{\circ} \mathrm{C}$ increase. AFM testing technology and image analysis method in this paper can be used for a reference in the nano-scale study of bitumen.
\end{abstract}

Keywords: bitumen; thermo-oxidative ageing; nano-morphology parameters; bee-like structure; technical indices

\section{Introduction}

Bitumen ageing refers to a series of physical and chemical changes that occur under the natural climatic conditions of light, oxygen, and water during the production, construction, and use [1-3]. Thermo-oxidative ageing accounts for more than $80 \%$ of the total life cycle ageing of bitumen [4-6]. Rotating thin film oven test (RTFOT) or thin film oven test (TFOT) is usually used to simulate the short-term ageing process of bitumen [7]. The technical indexes of bitumen after ageing have changed to a certain extent. Current studies suggest that the change in bitumen components is the cause of ageing [8-11]. Some of the light components, such as saturate and aromatic, are volatilized, and some of them are converted into resins, while some of the resins are converted into asphaltenes with larger 
molecular weight and greater hardness [12-14]. Zhang et al. [15] used the method of prolonging ageing time to obtain the ageing degree and ageing rate of bitumen in different periods. Poulikakos et al. [5] reported that the short-term ageing temperature had a significant effect on long-term chemical and rheological properties. Nare et al. [4] reported that the rheological properties of bitumen depended on its age state as related to thermal history. Hung and Fini [16] considered that absorption spectroscopy was useful to determine the extent of ageing resembling multiple periods of service life for bitumen. With the gradual development of micro-testing technology, the research on bitumen ageing has changed from macro-performance to micro-parameters [17].

In recent years, atomic force microscope (AFM) technology has been widely used in the field of bitumen testing $[18,19]$. Compared with scanning electron microscope (SEM), AFM test conditions do not require vacuum, avoiding volatilization, or sputtering of light components in bitumen [20]. More importantly, the AFM images have nanometer-scale high resolution, which can clearly observe the nano-morphological characteristics of bitumen [21,22]. In the AFM image, the bitumen has a structure similar to that of the bee body, which Loeber [23] named the bee-like structure. At present, there are still controversies about the formation mechanism of the bee-like structure [24]. There are two main viewpoints. Viewpoint 1 is that wax is the cause of the formation of bee-like structure, viewpoint 2 is that asphaltene is the root cause of the formation of bee-like structure [25-27]. Viewpoint 2 has been accepted by more and more scholars. The relationship between the nano-morphology characteristics of bitumen represented by bee-like structure and the macro-technical indexes of bitumen has become a hot topic. Huang et al. [28] observed the changes of bee-like structure in the process of loading by using AFM. Dai et al. [29] found that the number of bee-like structures decreased during ageing. Yu et al. [7] reported that the main reason for the nanomechanical changes during ageing or regeneration was the change of chemical composition of bitumen. Zhang et al. [17] considered that the ageing increased the surface stiffness, so the ageing affected the bitumen nano-morphology significantly. In summary, there are still some problems in the study of the relationship between the AFM nano-morphology and ageing of bitumen $[28,30,31]$.

(1) Lack of parameters and methods for quantitative analysis of nano-morphological parameters of bitumen;

(2) The effect of ageing on the nano-morphology of bitumen is not clear enough;

(3) The quantitative relationship between bitumen nano-morphology and technical indexes after ageing is not clear.

The purpose of this paper is to find out the effect of thermal oxygen ageing on the nano-morphology of bitumen. The research contents include the nano-morphological parameters of bitumen for quantitative analysis, the effects of ageing on the nano-morphology parameters of bitumen, and the quantitative relationship between bitumen nano-morphology and technical indices after ageing. The AFM testing technology and image analysis method in this paper can be used for reference in the nano-scale study of bitumen. The qualitative relationship between the nano-morphological parameters and the technical indexes of bitumen after ageing was clarified by the test results and the influence law of ageing on the nano-morphological parameters of bitumen was revealed.

\section{Materials and Methods}

In this paper, the preparation method of AFM samples of bitumen was designed. The area ratio of bee-like structure, the roughness, and the maximum amplitude were selected as the nano-morphological parameters of the bitumen. The calculation method of nano-parameters was also proposed. The bitumen with different ageing degrees was prepared by TFOT. The nano-morphological parameters of bitumen with different ageing degrees were obtained and analyzed, and the relationships between nano-morphological parameters and bitumen technical indexes after ageing were analyzed. Figure 1 is the technology roadmap of this paper. 


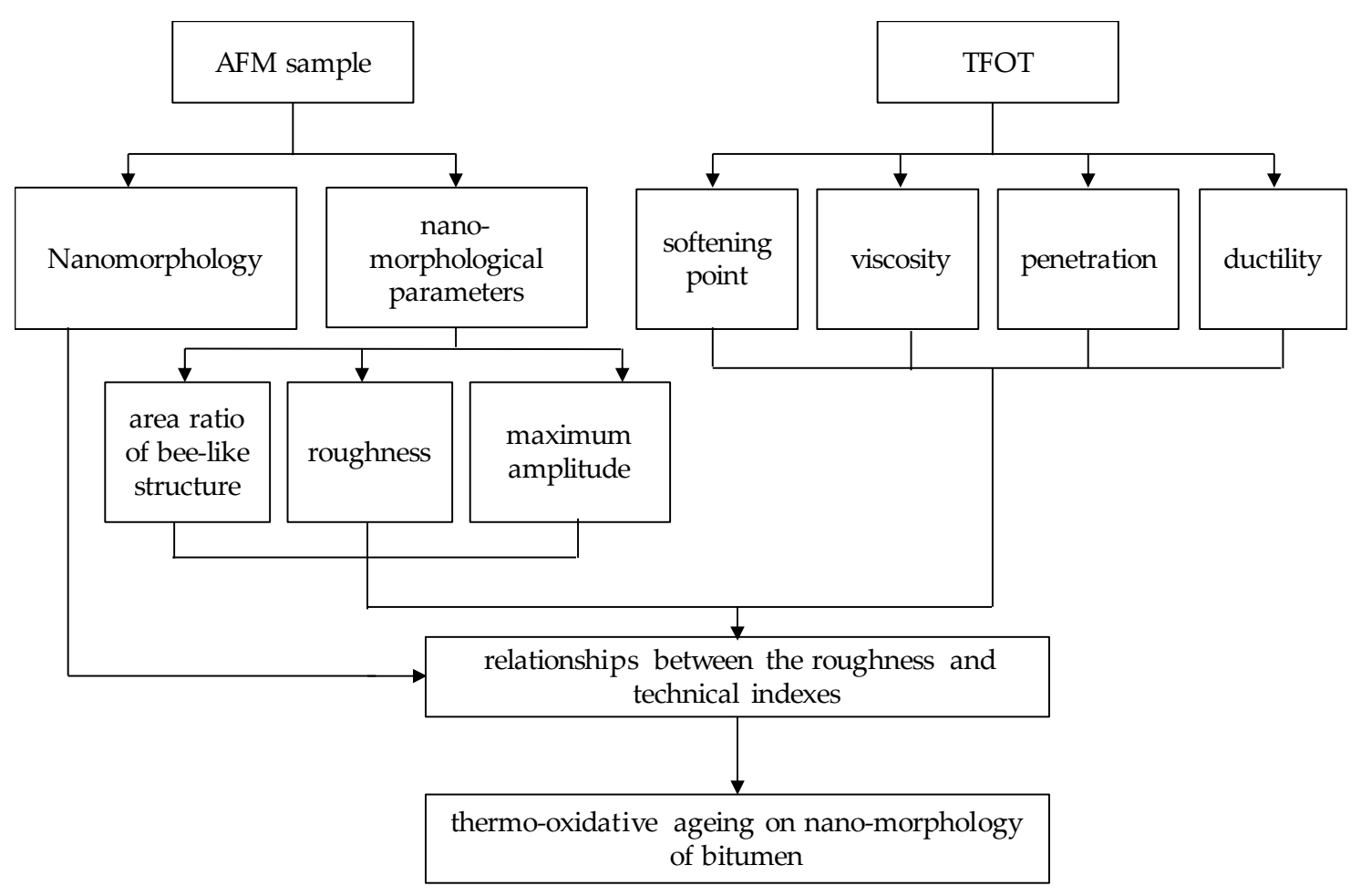

Figure 1. Technology roadmap of this paper.

\subsection{Bitumen}

The bitumen used in this paper was A-90 bitumen, which was produced by Sinopec Qilu Petrochemical Company (Zibo, China). The technical indexes are shown in Table 1.

Table 1. A-90 bitumen technical indexes.

\begin{tabular}{|c|c|c|}
\hline Test Items & Measured Value & Standard [32] \\
\hline Ductility at $10{ }^{\circ} \mathrm{C}, \mathrm{cm}$ & 97.5 & $\nless 30$ \\
\hline Viscosity at $60^{\circ} \mathrm{C}, \mathrm{Pa} \cdot \mathrm{s}$ & 204.8 & $\nless 160$ \\
\hline Ductility at $15^{\circ} \mathrm{C}, \mathrm{cm}$ & $>100$ & $\nless 100$ \\
\hline Penetration at $25^{\circ} \mathrm{C}, 0.1 \mathrm{~mm}$ & 86.6 & $80-100$ \\
\hline Density, $\mathrm{g} / \mathrm{cm}^{3}$ & 0.998 & - \\
\hline Softening point, ${ }^{\circ} \mathrm{C}$ & 45.0 & $\ngtr 45$ \\
\hline Residue Ductility at $15^{\circ} \mathrm{C}, \mathrm{cm}$ & 29.4 & $\nless 20$ \\
\hline Quality loss, \% & 0.1 & \pm 0.8 \\
\hline Residue penetration ratio, $\%$ & 71.8 & $\nless 57 \%$ \\
\hline
\end{tabular}

TFOT: Thin Film Oven Test.

\subsection{Preparation of Atomic Force Microscopes (AFM) Samples}

In this paper, the thermo-oxygen ageing treatment of asphalt was carried out by thin film oven (model number, LBH-1) which was produced by Nanjing Soil Instrument Factory CO., LTD. (Nanjing, China). The temperature of bitumen during the test was $163^{\circ} \mathrm{C}$, the turning disc rotated at a speed of $5.5 \pm 1 \mathrm{r} / \mathrm{min}$ on the horizontal plane, and the tilt angle between the turning disc and the horizontal plane was not more than $3^{\circ}$. The existence of the angle helps the bitumen to form a film during the rotation process, which contributes to the ageing process. An angle of not more than $3^{\circ}$ is helpful to the uniformity of bitumen film. The test equipment and test conditions are shown in Figure 2. 


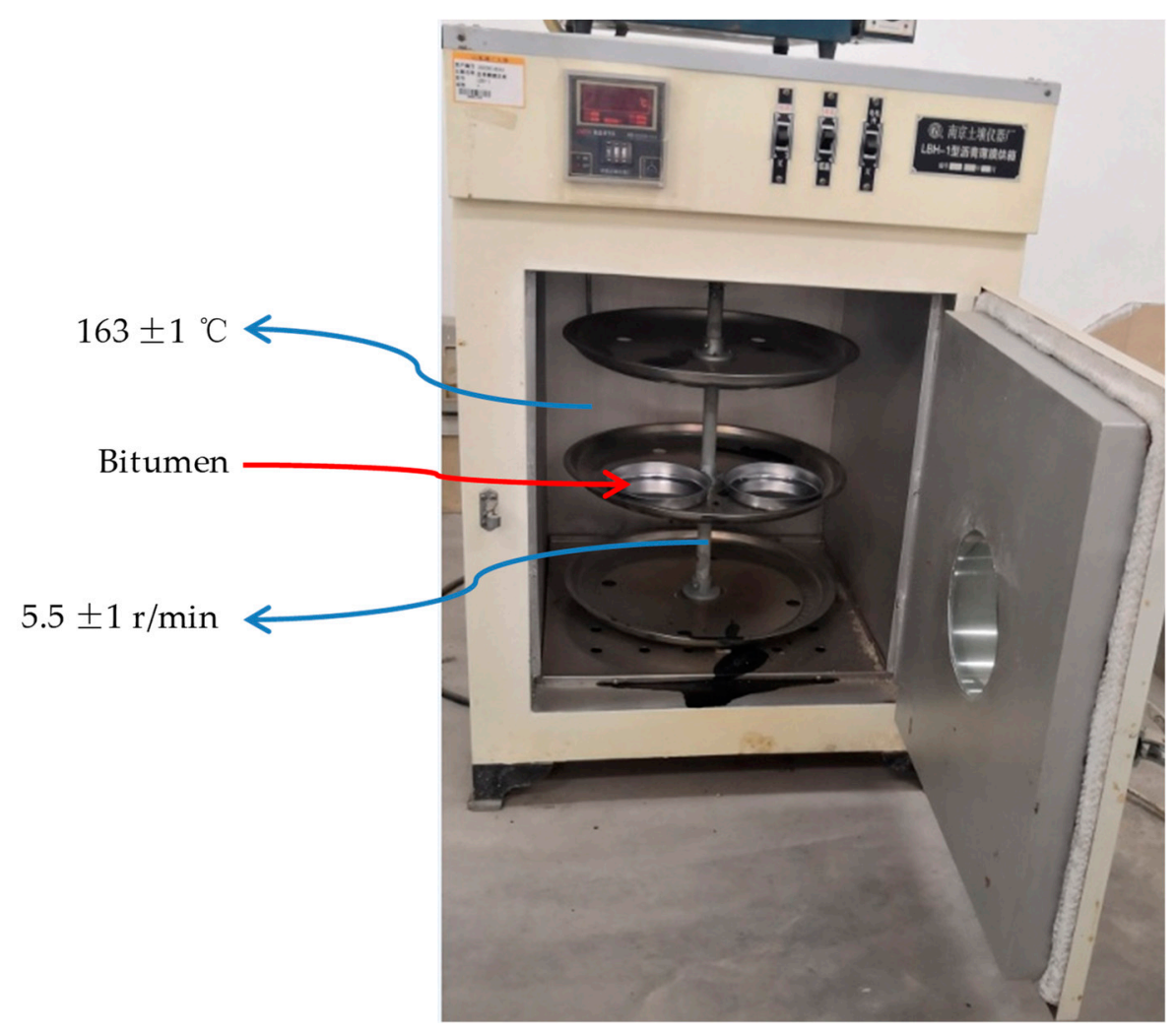

Figure 2. The test equipment and test conditions.

The AFM samples were prepared by using the aged bitumen, and the steps are shown as follows $[20,33,34]$. Firstly, at the temperature of $145^{\circ} \mathrm{C}$, the bitumen was picked up by a glass rod and dropped on the glass slide. Secondly, the slide was moved to the horizontal frame, and the bottom was heated slightly to make the bitumen lie flat. Finally, the samples were cooled at room temperature for $15 \mathrm{~min}$, and the surface of the bitumen was covered with a glass container to prevent samples contamination. Photograph of the AFM sample preparation process is shown in Figure 3.

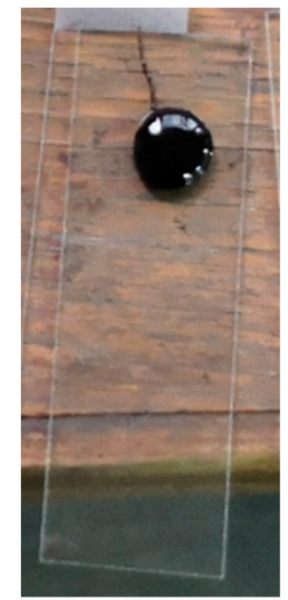

(a)

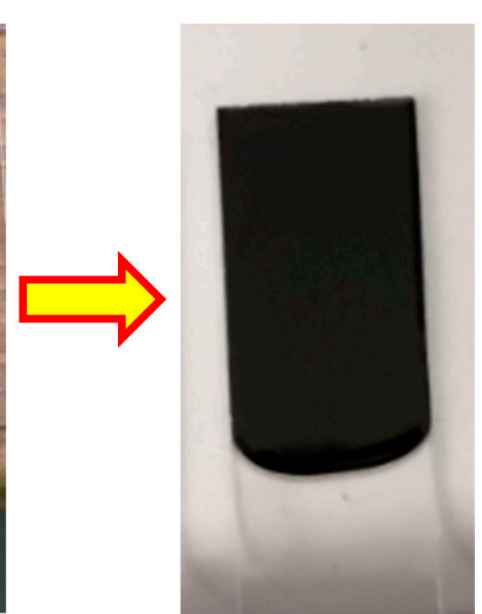

(b)

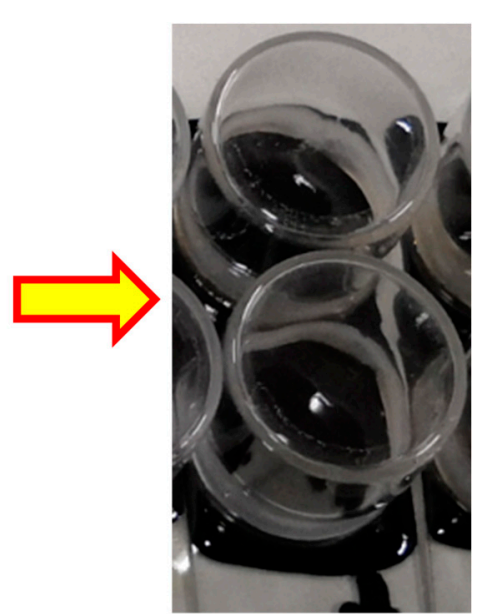

(c)

Figure 3. Photograph of the atomic force microscope (AFM) sample preparation process. (a) bitumen; (b) horizontal treatment; (c) Dust-proof treatment. 


\subsection{Atomic Force Microscope (AFM) Test Conditions and Methods}

The AFM used in this paper was produced by Bruker Company (Rheinstetten, Germany). The measurement principle is that the force between the probe of the cantilever and the atom of the sample is sensed and amplified by a micro-cantilever, so as to achieve the purpose of detection with atomic resolution [35]. The test conditions are shown in Table 2.

Table 2. Test conditions of atomic force microscope (AFM).

\begin{tabular}{cc}
\hline Test Conditions & Value \\
\hline Scan size & $10 \mu \mathrm{m} \times 10 \mu \mathrm{m}$ \\
Temperature & $25{ }^{\circ} \mathrm{C}$ \\
Samples number & 255 \\
Scan rate & $2.5 \mathrm{~Hz}$ \\
Drive amplitude & $300.00 \mathrm{mV}$ \\
\hline
\end{tabular}

Scan size determines the scanning range. Temperature is a necessary parameter for experiments, the results are different at different temperatures. Samples number is the number of sampling points. Scan rate is the rate at which the needle tip scans back and forth on the surface. Drive amplitude determines the height range.

\subsection{Test Methods}

TFOT was carried out on the bitumen. The ageing time was $0 \mathrm{~h}, 2.5 \mathrm{~h}, 5 \mathrm{~h}, 7.5 \mathrm{~h}, 10 \mathrm{~h}, 15 \mathrm{~h}$, and $20 \mathrm{~h}$, respectively [36-40]. TFOT is known as a short-term ageing test method. Although the ageing of the bitumen after mixing and transportation processes occurs at lower temperatures, the final results of ageing are similar. For example, TFOT ageing for $20 \mathrm{~h}$ is equivalent to the ageing of bitumen at the end of its life. The bitumen samples with different ageing time were determined by AFM, and the penetration, ductility, softening point, and viscosity of the bitumen after ageing were tested.

\subsubsection{Analysis Nano-Morphological Characteristics of Bitumen}

The nanoscope analysis software was used to analyze the AFM images, the three-dimensional height images, the two-dimensional height images, the amplitude images, and the phase images could be obtained, as shown in Figure 4.

The three-dimensional image in Figure 4 can reflect the height fluctuation of the bitumen surface in a three-dimensional manner. The size and distribution of the bee structure on the bitumen surface can be found in the two-dimensional height image. The amplitude image reflects the degree of hardness and softness of bitumen materials in different areas. It can be seen from Figure $4 \mathrm{~b}$ that there are bee-like structures on the bitumen surface, and the height of the bee-like structure is relatively high, while the fluctuation of other areas is basically flat. The surface characteristics of the bee-like structure are shown in Figure 5 [20-22].

As can be seen from Figure 5, the bee-like structure of the bitumen is generally oval [23], similar to the body of bees. The bee-like structure is basically perpendicular to the bitumen-air interface, showing a high-low fluctuation. As can be seen from Figure $5 b$, the wave crest and wave trough of a single bee-like structure alternately appear in three-dimensional space. In order to better describe the characteristics of the bee-like structure, the representative areas in bitumen AFM images were chosen and analyzed by using the section function of nanoscope analysis. The results are shown in Figure 6. 


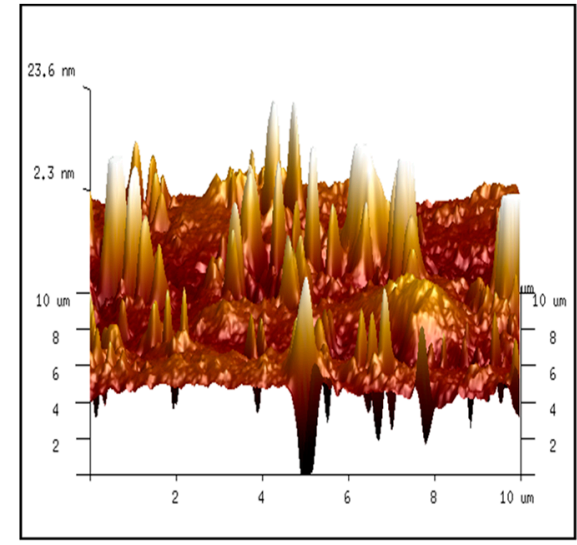

(a)

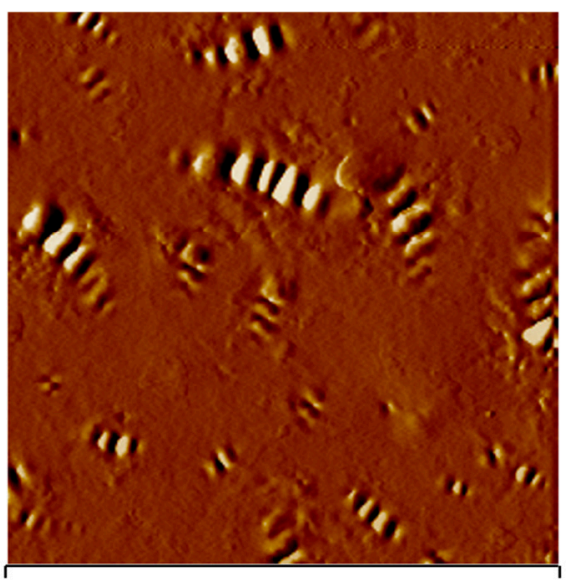

0.0

(c)

$10 \mu \mathrm{m}$

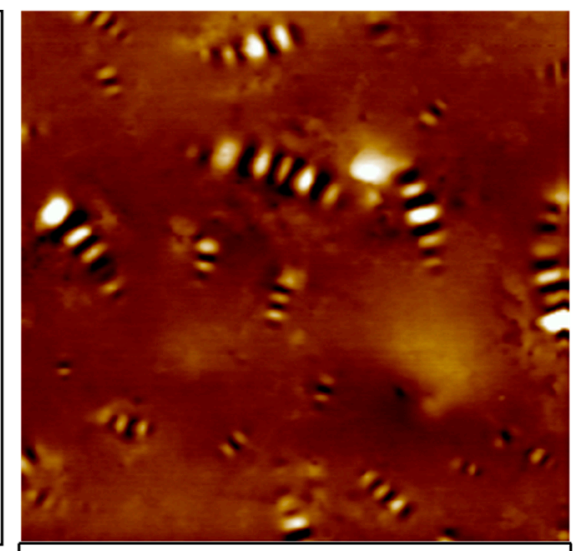

0.0

(b)

$10 \mu \mathrm{m}$

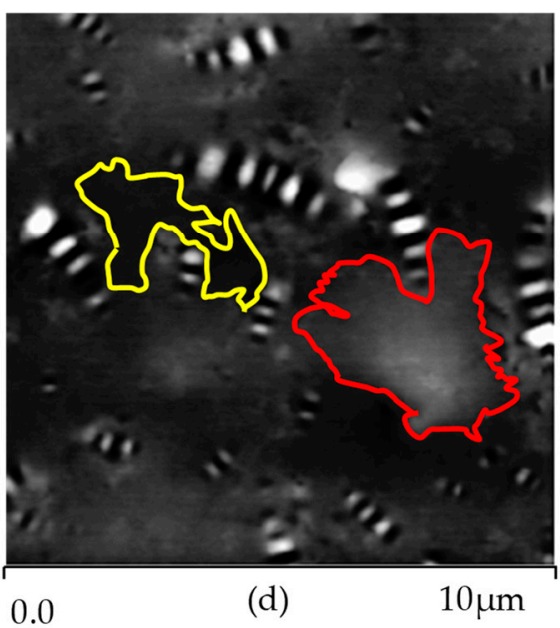

Figure 4. Atomic force microscope (AFM) images of bitumen without ageing. (a) three-dimensional height image; (b) Two-dimensional height image; (c) amplitude image; (d) Phase image.

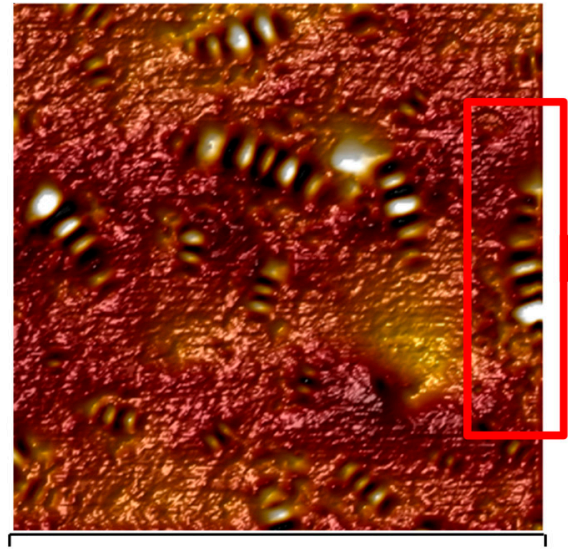

0.0

(a)

$10 \mu \mathrm{m}$

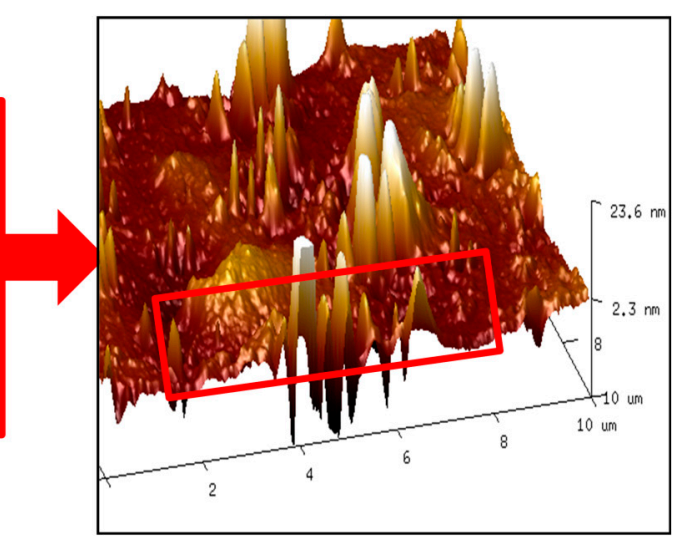

(b)

Figure 5. Bee-like structure image. (a) the interception point of the bee structure; (b) the three-dimensional height image corresponding to the interception point. 


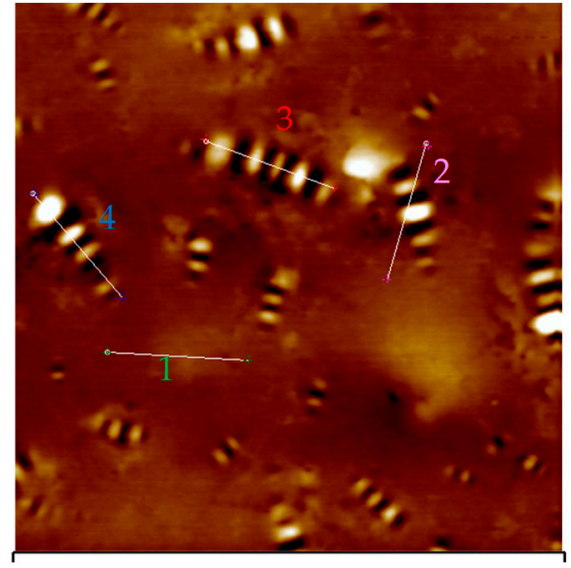

0.0

(a)

$10 \mu \mathrm{m}$

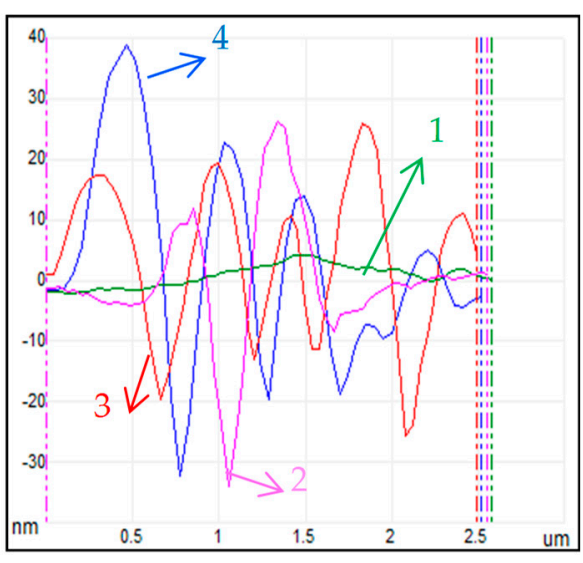

(b)

Figure 6. Height curves of representative areas in bitumen atomic force microscope (AFM) images (a) area selection; (b) height curves; (1) away from bee-like structure area; (2) bee-like structure and adjacent area; (3) and (4) bee-like structures.

Three different types of areas are selected in Figure 6a, the area away from the bee-like structure, the bee-like structure and adjacent area, and the bee-like structures. Figure $6 \mathrm{~b}$ contains the surface height curves of different areas, and it is shown by area 1 that the height change range of the bitumen surface away from the bee-like structure area is very small. The surface height of the bee-like structure fluctuates greatly, but once it leaves the range of the bee-like structure, the surface height fluctuates will rapidly decrease. The bee-like structure in the AFM image is composed of wave crest and wave trough. The wave crest is bright and the wave trough is dark.

\subsubsection{Nano-Morphological Parameters}

Based on the analysis of nano-morphology of bitumen, three nano-morphological parameters, such as the area ratio of bee-like structure, the roughness, and the maximum amplitude, are proposed in this paper. A brief explanation is as follows.

- The Area Ratio of Bee-like Structure

The bee-like structure is a unique nanostructure of bitumen, and its quantity and area may be related to the technical indexes of bitumen. In this paper, the area ratio of the bee-like structure in the AFM image was measured and calculated by the following methods: Firstly, the bee-like structure in the AFM image is removed by using Photoshop software as shown in Figure 7a,b [41]; Secondly, the measure function of Image-Pro-Plus software is used to encode the bee-like structure and read the pixel points $P_{i}$, as shown in Figure 7c,d [42,43]; Finally, the area ratio of the bee-like structure can be calculated according to Equation (1). All the images in this paper are $256 \times 256$ pixels, and the pixels are not changed during image processing.

$$
P_{B S A}=\sum_{1}^{i} P_{i} / P, \%
$$

where $P_{B S A}$ is the area ratio of bee-like structure; $P_{i}$ is the area of bee-like structure which is encoded number $i ; P$ is the total area of the AFM image. 


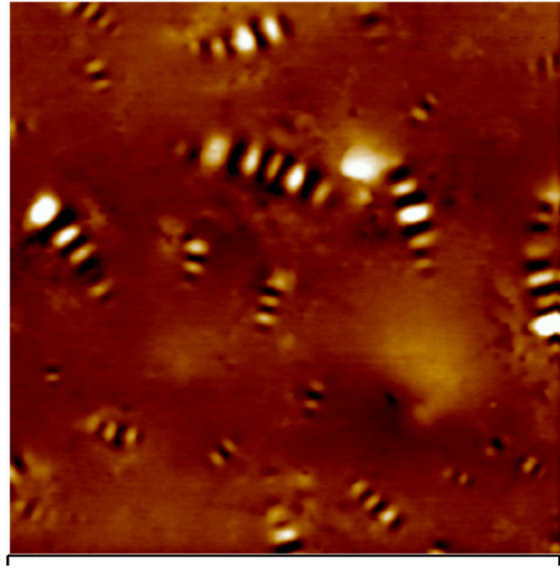

(a)

0.0

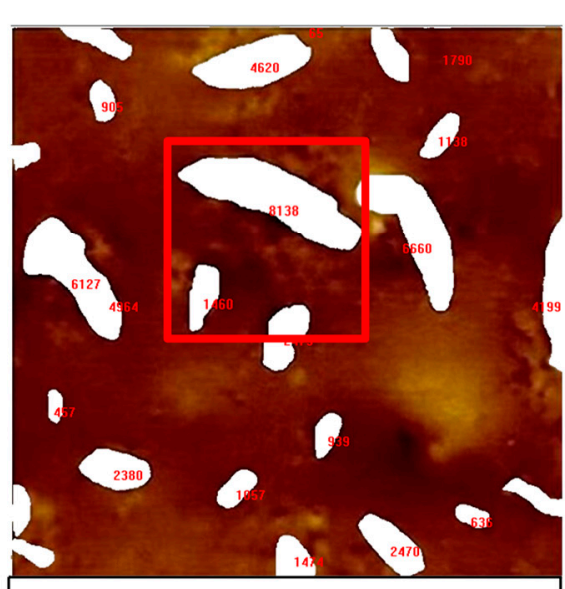

0.0 (c)
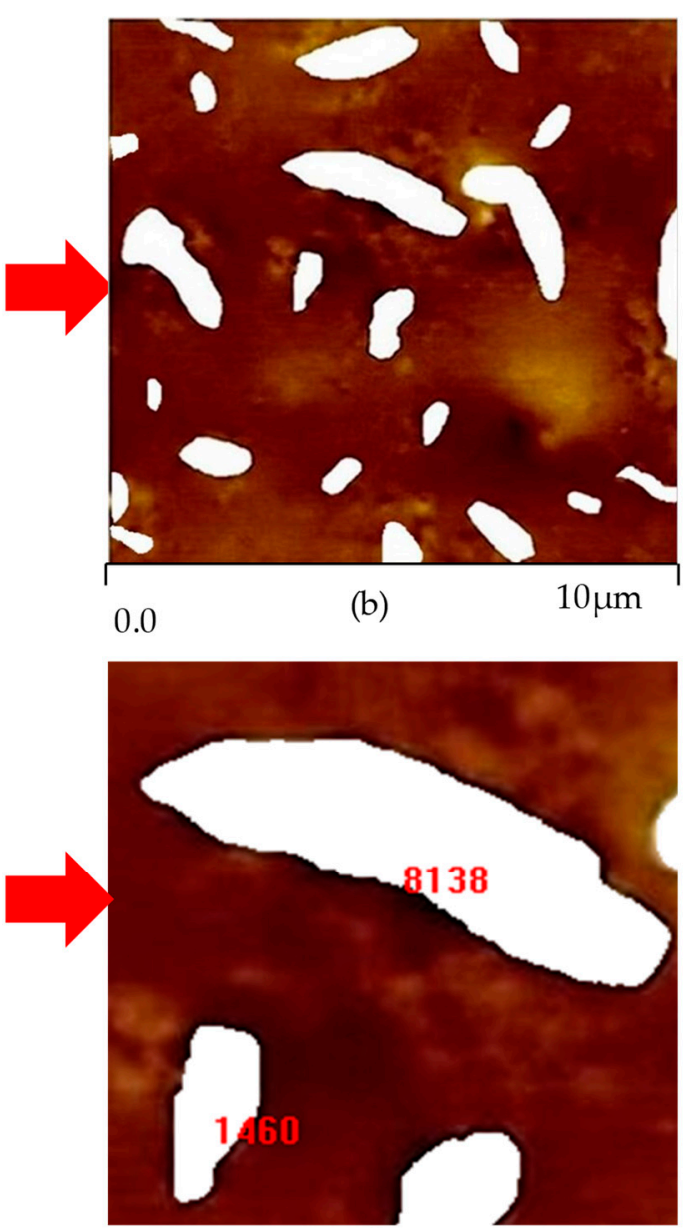

(d)

Figure 7. Bee-like structure area measurement. (a) two-dimensional bitumen atomic force microscope (AFM) image; (b) bee-like structure removal image; (c) calculation image of bee-like structure area; (d) partial enlargement image of calculation results of bee-like structure).

- The Maximum Amplitude

In the bitumen AFM image, the height of the bee-like structure fluctuates along its major axis [44]. It is not difficult to find that the surface height of the bee-like structure fluctuates in the form of waves, and the wavelength is basically the same, but the wave crest and wave trough are different. The maximum height difference between the wave crest and wave trough is defined as amplitude, as shown in Figure 8.

Amplitude response is the intensity of fluctuation of bee-like structure, and it is also a parameter to describe the development of the bee-like structure. The maximum amplitude of bee-like structure can be obtained by measuring all bee-like structures in the AFM image.

\section{- The Roughness}

The area ratio of the bee structure can be described as the proportion of the area of the bee structure in the two-dimensional image. The degree of the single bee structure development can be described by the amplitude. However, in the three-dimensional image, the surface area of the bee structure needs to include the two-dimensional area and three-dimensional amplitude of the bee structure. Fortunately, the roughness just meets these two requirements. In this paper, the root means square roughness is 
used to describe the surface structure characteristics of bitumen. The calculation method is shown in Equation (2) [44].

$$
R_{q}=\left(\frac{\iint\left[h(x, y)-h_{0}\right]^{2} d A}{\iint d A}\right)^{1 / 2}
$$

where $A$ is the scanning area, $10 \mathrm{um} \times 10 \mathrm{um}$ in this paper; $h(x, y)$ is the height equation, $\mathrm{nm} ; h_{0}$ is the reference height, and its equation is shown in Equation (3) [45].

$$
h_{0}=\frac{\iint h(x, y) d A}{\iint d A}
$$

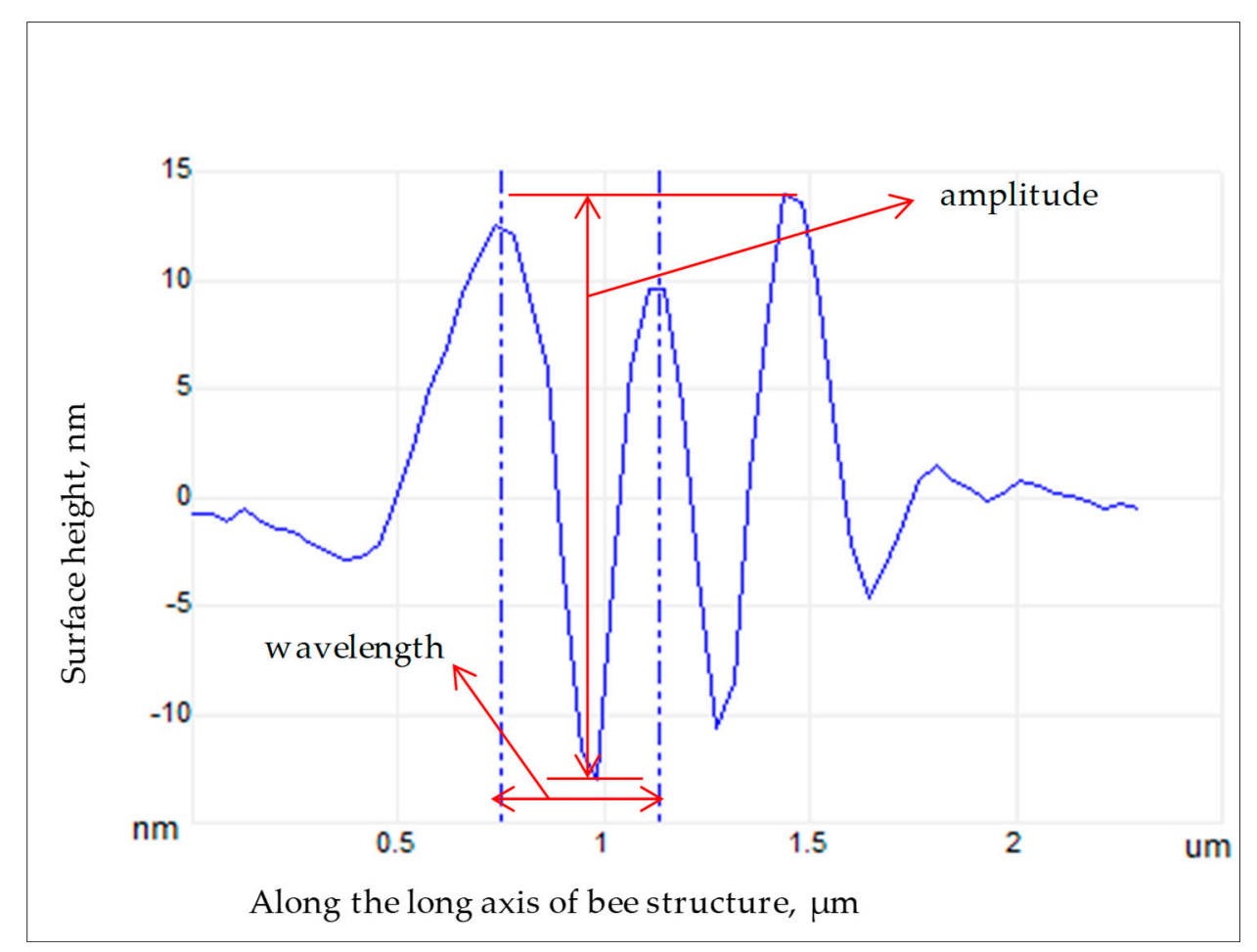

Figure 8. The maximum amplitude.

\section{Nano-Morphological Parameters and Technical Indexes of Aged Bitumen}

\subsection{Nano-Morphological Parameters Test Results of Aged Bitumen}

The A-90 bitumen samples with different ageing time were tested by AFM. The three-dimensional nanoscopic images of A-90 bitumen under different ageing time are shown in Figure 9.

With the ageing time prolonging, the number of the bitumen bee-like structure decreases gradually, but the bee-like structures aggregate with each other to form larger bee-like structures. Relevant studies have shown that the existence of asphaltene is an important cause of the formation of the bee-like structure. During the bitumen ageing process, some light components volatilize, some aromatics change into resins, and some resins are converted into asphaltenes. The asphaltenes will move closer together and agglomerate due to the increase in the proportion of asphaltenes, thereby, the number of bee-like structures will reduce and the volume will increase. These phenomena also indicate that ageing can promote the development of the bee-like structure [46-49]. The relationship between nano-morphological parameters and ageing time is shown in Figure 10. 


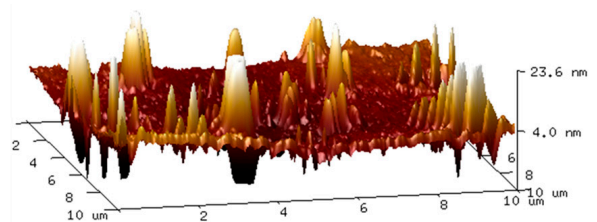

(a)
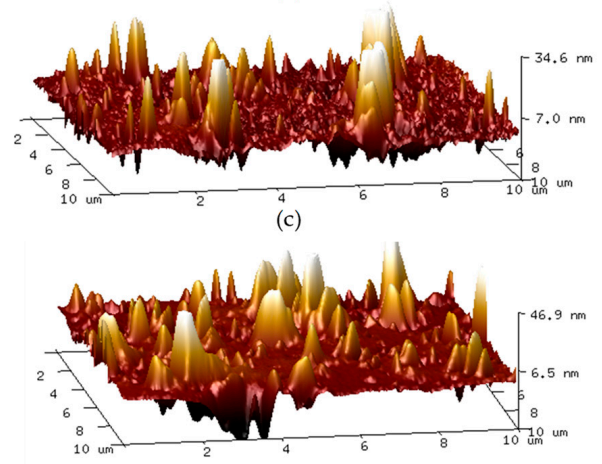

(e)

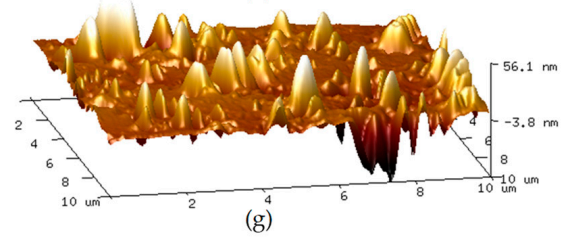

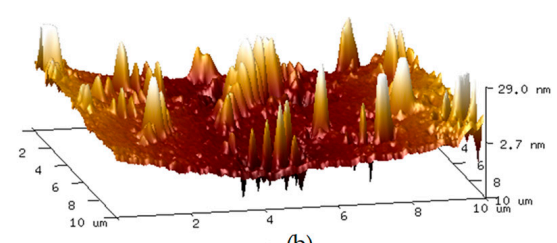

(b)

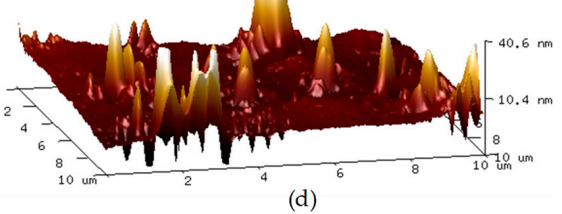

(d)

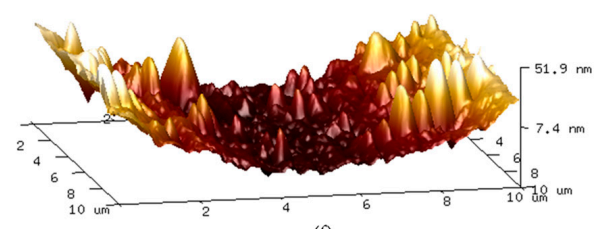

(f)

Figure 9. The three-dimensional nanoscopic images of A-90 bitumen under different ageing time. (a) 0 h; (b) $2.5 \mathrm{~h}$; (c) $5 \mathrm{~h}$; (d) $7.5 \mathrm{~h}$; (e) $10 \mathrm{~h}$; (f) $15 \mathrm{~h}$; (g) $20 \mathrm{~h}$.

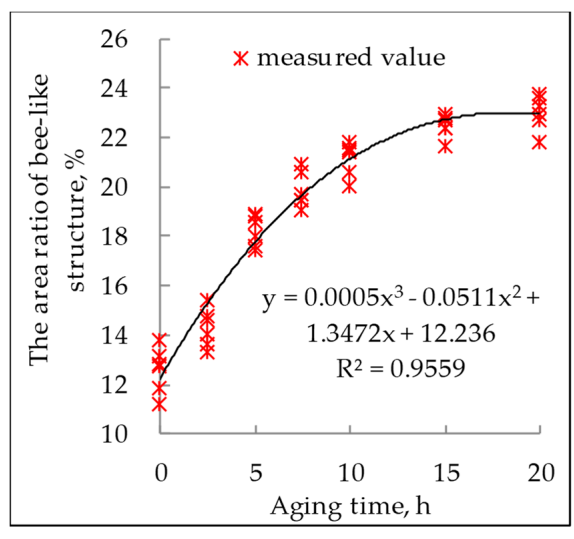

(a)

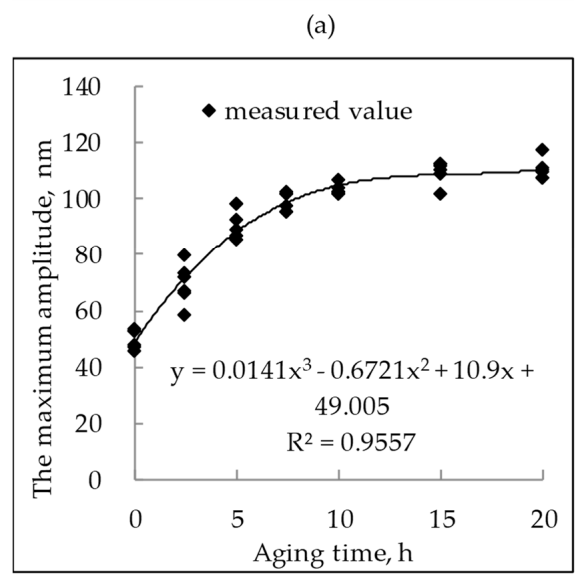

(c)

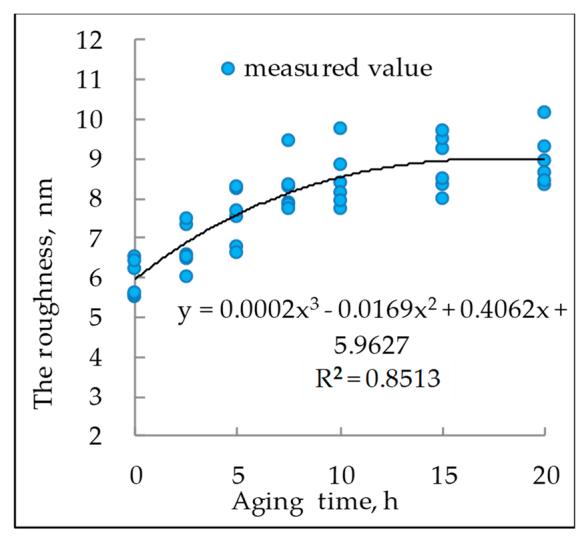

(b)$$
\text { . }
$$ 
Figure 10 shows that as the ageing time is prolonged, the area ratio of the bee-like structure increases gradually and tends to be stable after ageing time is longer than $15 \mathrm{~h}$. The surface roughness increases with ageing time and tends to be stable after ageing time is longer than $15 \mathrm{~h}$. The maximum amplitude has a similar regular pattern and does not increase after ageing for $10 \mathrm{~h}$. The change of nano-morphological parameters indicates that the bee-like structure has been further developed during the ageing process. It can be concluded that ageing has an effect on the nano-morphology of asphalt. During the ageing of the bitumen, the composition continuous changes. Saturate and aromatic are continuously volatilized and partially converted into the resin, some of which are converted into asphaltenes. Also, asphaltenes aggregate with each other.

\subsection{Relation Between Nano-Morphological Parameters and Technical Indexes of Bitumen After Ageing}

Ageing also affects the pavement performances of bitumen. In this paper, the relationship between nano-morphological parameters and pavement indexes of A-90 bitumen before and after ageing was established based on the test results. The bee-like structure and penetration, ductility, softening point, and viscosity of A-90 bitumen are shown in Figure 11.

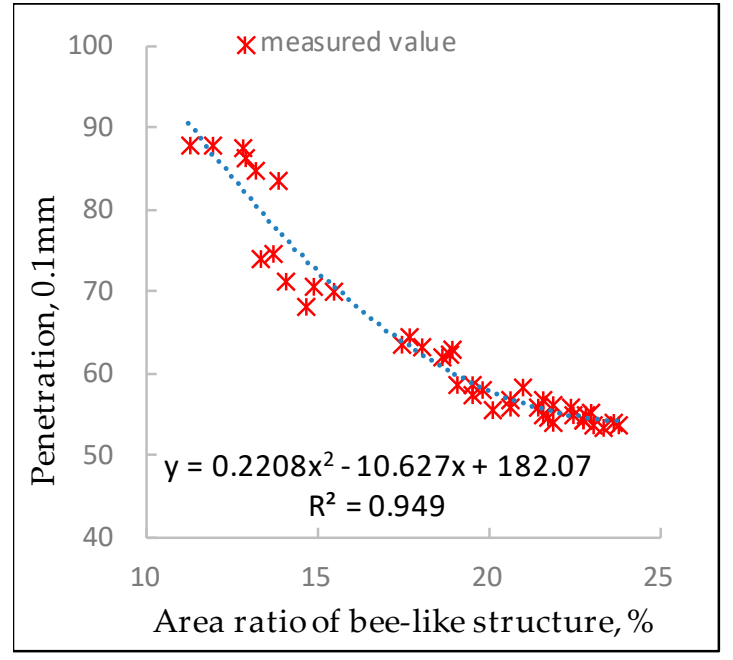

(a)

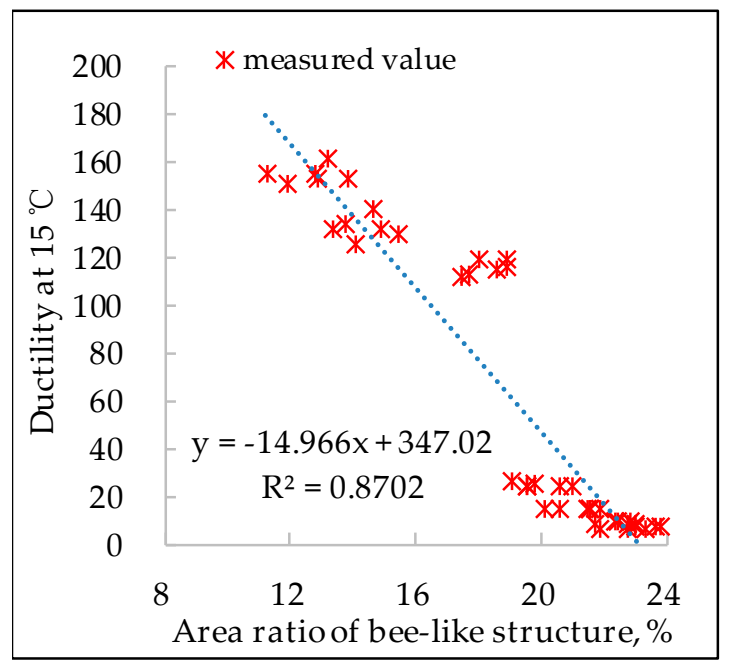

(c)

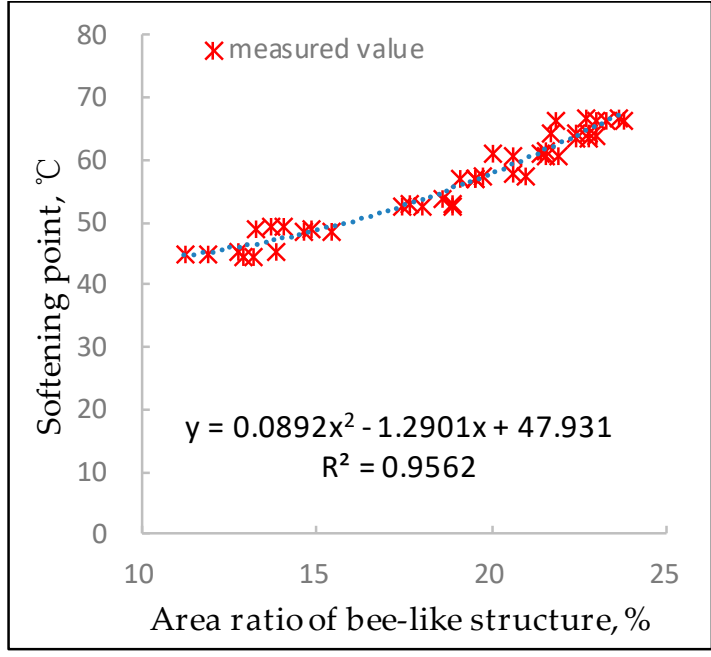

(b)

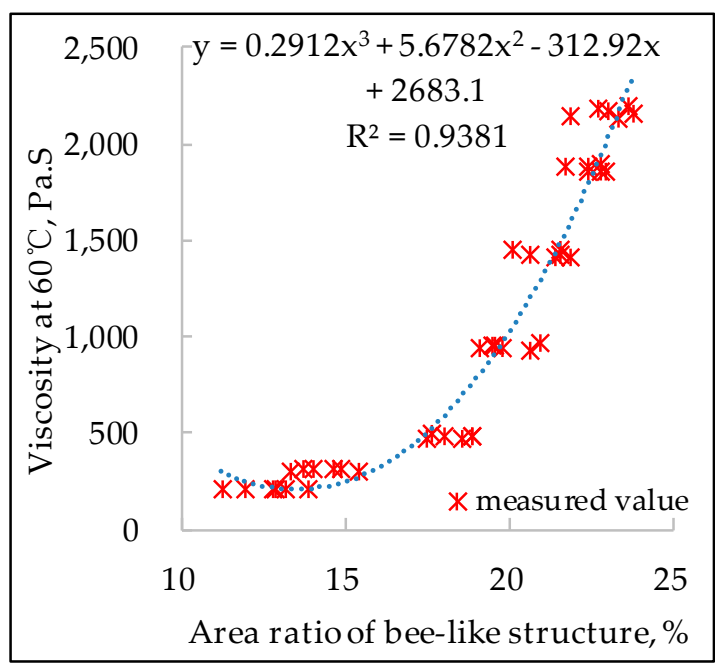

(d)

Figure 11. The relationships between the area ratio of the bee-like structure and technical indexes. (a) penetration at $25^{\circ} \mathrm{C}$; (b) softening point; (c) ductility at $15^{\circ} \mathrm{C}$; (d) viscosity at $60^{\circ} \mathrm{C}$. 
Figure 11 shows that the area ratio of the bee-like structure has a certain correlation with penetration, ductility, softening point, and viscosity of A-90 bitumen. With the increases in the area ratio of bee-like structure, the penetration of bitumen decreases, the softening point increases, and the viscosity at $60^{\circ} \mathrm{C}$ increases. Penetration and softening point are the evaluation indexes of bitumen viscosity under specific conditions, and viscosity at $60^{\circ} \mathrm{C}$ is a direct evaluation index of bitumen viscosity, therefore, the area ratio of the bee-like structure is bound to be related to the viscosity of asphalt, i.e., the bigger the area ratio of the bee-like structure, the bigger the viscosity of the bitumen. The area ratio of the bee-like structure is linear with the bitumen ductility (correlation coefficient is $87.02 \%$ ), i.e., the bigger area ratio of the bee-like structure, the smaller the ductility at $15^{\circ} \mathrm{C}$ of bitumen.

The relationships between the roughness and technical indexes of A-90 bitumen are shown in Figure 12.

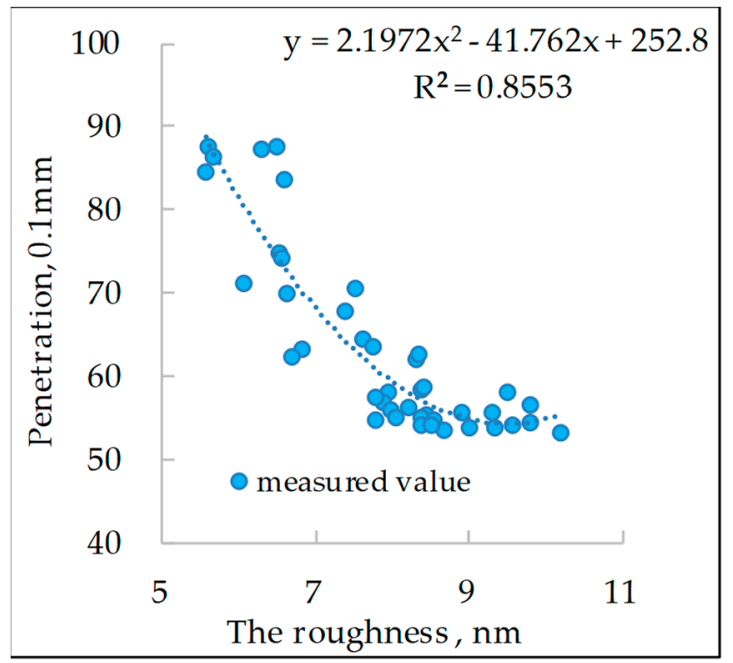

(a)

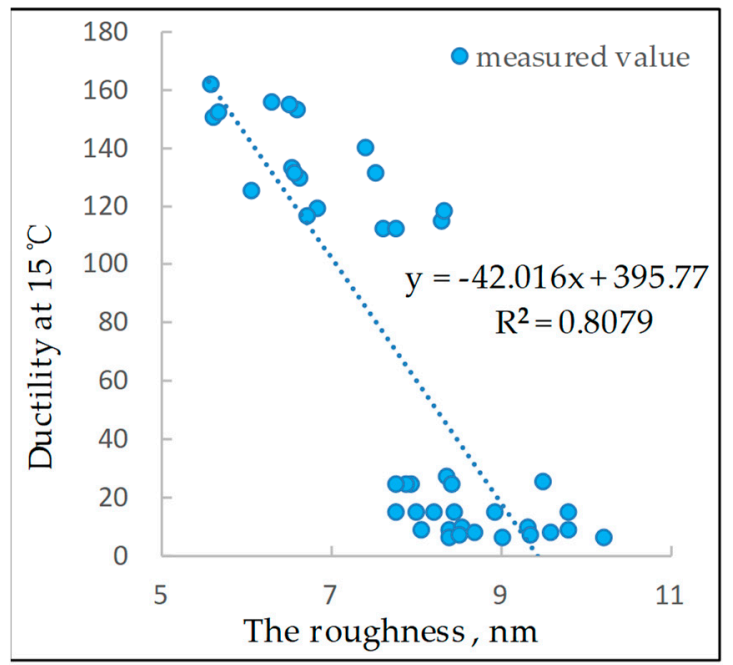

(c)

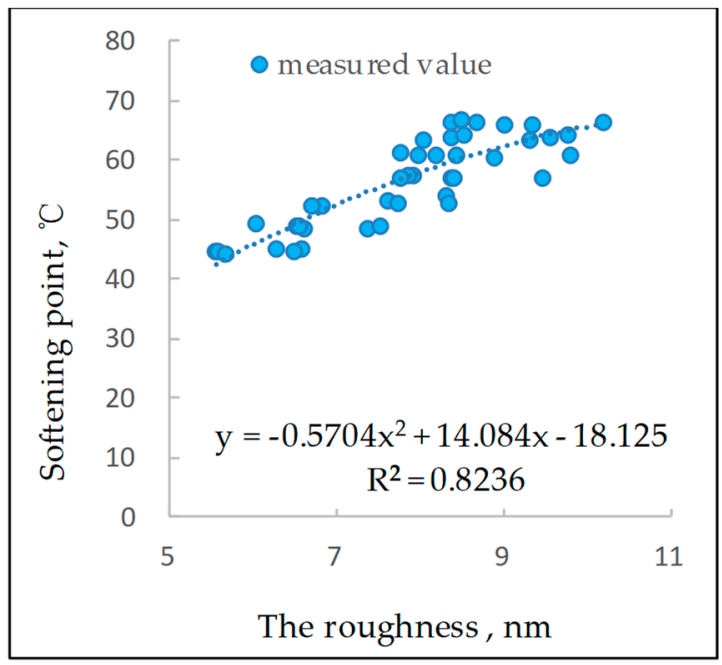

(b)

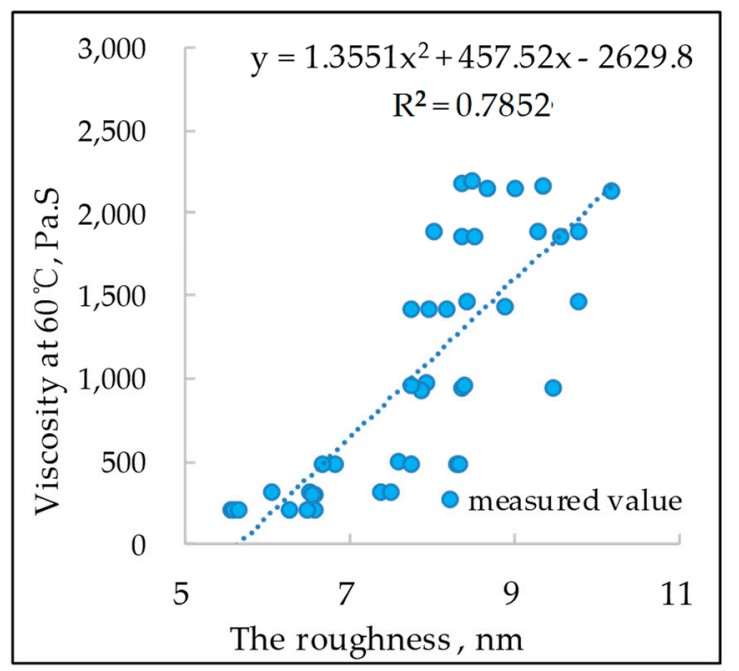

(d)

Figure 12. The relationships between the roughness and technical indexes. (a) penetration at $25^{\circ} \mathrm{C}$; (b) softening point; (c) ductility at $15^{\circ} \mathrm{C}$; (d) viscosity at $60^{\circ} \mathrm{C}$.

It can be seen from Figure 12 that with the increases of roughness, the viscosity at $60^{\circ} \mathrm{C}$ and the softening point of A-90bitumen increase obviously, while the penetration at $25^{\circ} \mathrm{C}$ and the ductility at $15{ }^{\circ} \mathrm{C}$ decrease. However, compared with the correlation between the area ratio of the bee-like structure and the bitumen technical indexes, the relationship between roughness and technical indexes is relatively discrete. The reason for this phenomenon is probably due to the change in bitumen 
composition. The increase in asphaltene content is likely to be the main reason. During the ageing of the bitumen, the composition continuous changes. Saturate and aromatic are continuously volatilized and partially converted into the resin, some of which are converted into asphaltenes. Also, asphaltenes aggregate with each other.

The relationships between the maximum amplitude and technical indexes of A-90 bitumen are shown in Figure 13.

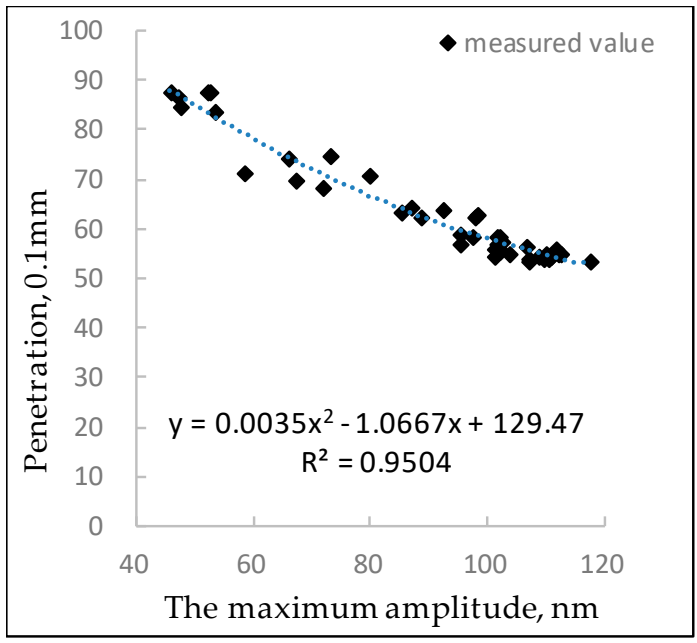

(a)

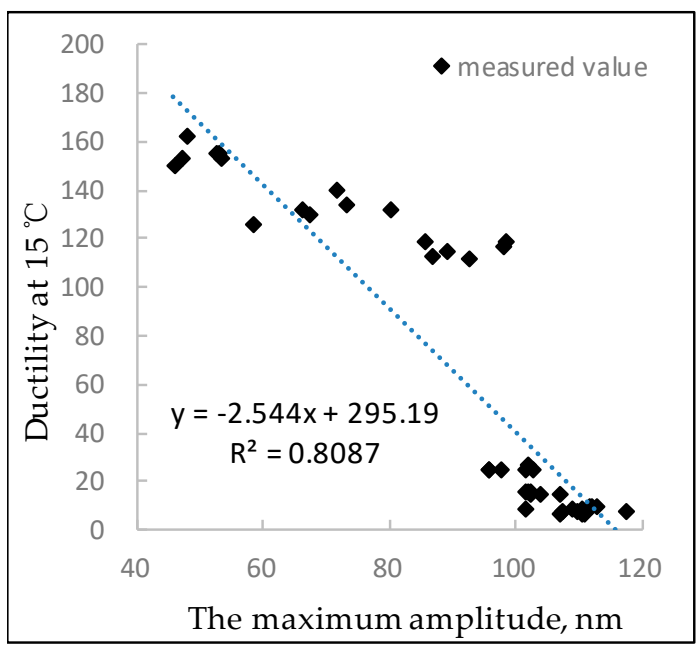

(c)

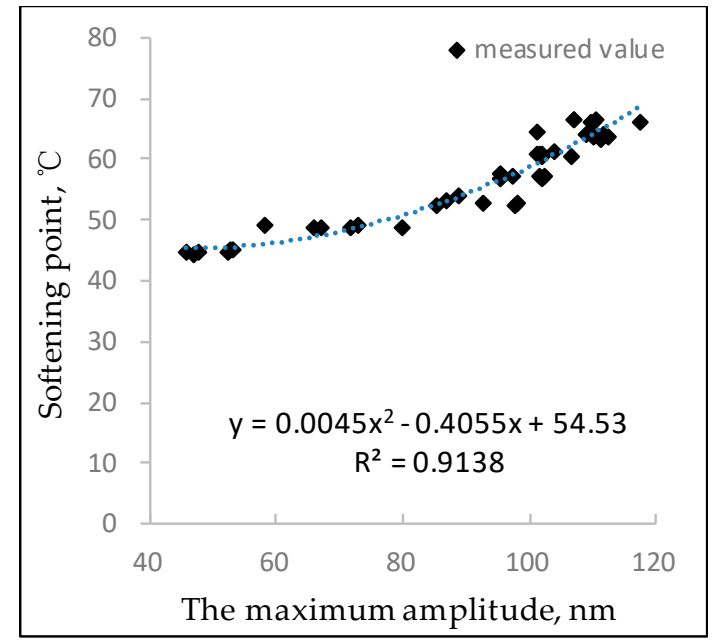

(b)

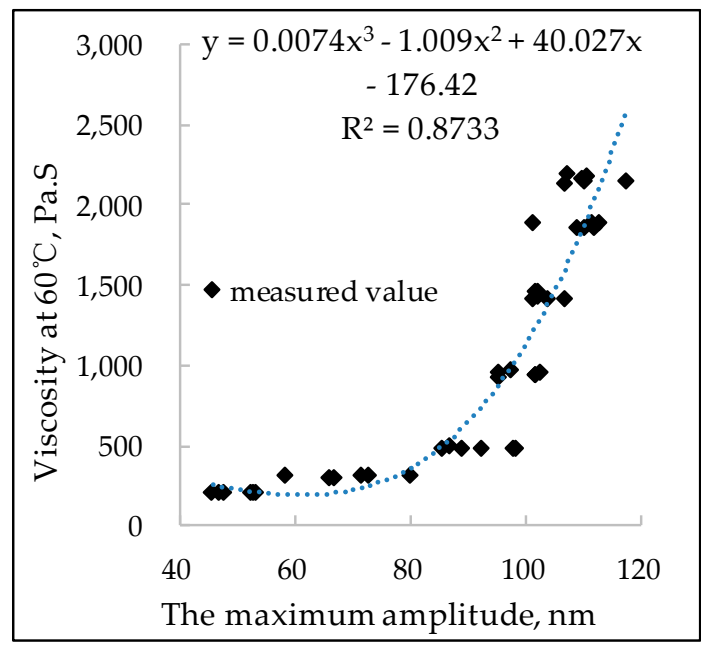

(d)

Figure 13. The relationships between the maximum amplitude and technical indexes. (a) penetration at $25^{\circ} \mathrm{C}$; (b) softening point; (c) ductility at $15{ }^{\circ} \mathrm{C}$; (d) viscosity at $60^{\circ} \mathrm{C}$.

The maximum amplitude is intrinsically related to the development of the bee-like structure. The larger the single volume of the honeycomb structure, the larger the maximum amplitude. The bee-like structure of bitumen after ageing is well developed and the larger the area ratio of the bee-like structure, the larger the maximum amplitude. As shown in Figure 13, the relationship between the maximum amplitude and bitumen-related technical indexes are similar to that between the area ratio of the bee-like structure and bitumen-related technical indexes. With the increase of the maximum amplitude, the penetration at $25^{\circ} \mathrm{C}$ decreases, the softening point increases, the ductility at $15{ }^{\circ} \mathrm{C}$ decreases, and the viscosity at $60^{\circ} \mathrm{C}$ increases. 


\section{Conclusions}

In this paper, the preparation method of AFM samples of bitumen was designed. Area ratio of bee-like structure, roughness, and maximum amplitude were selected as the nano-morphological parameters of the bitumen. The calculation method of nano-parameters was also proposed. Bitumen with different ageing degrees was prepared by TFOT. Nano-morphological parameters of bitumen with different ageing degrees were obtained and analyzed, and the relationships between nano-morphological parameters and bitumen technical indexes after ageing were analyzed.

(1) In the AFM image of bitumen, the bee-like structure height of bitumen is constantly changing, with alternating wave crests and wave troughs, but the height of the areas away from the bee-like structure is relatively stable.

(2) As the ageing time of the bitumen is prolonged, the bee-like structure on the bitumen surface has been further developed, i.e., the bee-like structures are aggregated mutually to form a larger bee-like structure.

(3) With the ageing time prolonging, the nano-morphological parameters of bitumen, such as the area ratio of bee-like structure, the roughness, and the maximum amplitude, increase gradually, but the growth rate is smaller and smaller with the ageing time prolonging.

(4) There is a close relationship between the nano-morphological parameters and the technical indexes of bitumen. During the ageing process of bitumen, with the increase of nano-morphological parameters (the area ratio of bee-like structure, the roughness, and maximum amplitude), the penetration at $25{ }^{\circ} \mathrm{C}$ and the ductility at $15{ }^{\circ} \mathrm{C}$ of the bitumen decrease, the softening point and the viscosity at $60^{\circ} \mathrm{C}$ increase.

Author Contributions: Data curation, L.Z., Y.L. and P.S.; Formal analysis, L.Z. and F.W.; Funding acquisition, W.Z.; Investigation, Z.J., F.W. and Y.L.; Methodology, W.Z., F.W. and P.S.; Project administration, W.Z.; Software, W.Z., L.Z., Z.J. and Y.L.; Writing-original draft, W.Z.

Funding: This work was funded by Zhangdian District Science and Technology Bureau, China, grant number 9001-118232; and the National Natural Science Foundation of China, grant number 51808327.

Conflicts of Interest: The authors declare no conflict of interest.

\section{References}

1. Cuciniello, G.; Leandri, P.; Filippi, S.; Presti, D.L.; Losa, M.; Airey, G. Effect of ageing on the morphology and creep and recovery of polymer-modified bitumens. Mater. Struct. 2018, 51, 136. [CrossRef]

2. Bressi, S.; Carter, A.; Bueche, N.; Dumont, A.G. Impact of different ageing levels on binder rheology. Int. J. Pavement Eng. 2016, 17, 403-413. [CrossRef]

3. Zhang, W.; Jia, Z.; Zhang, Y.; Hu, K.; Ding, L.; Wang, F. The effect of direct-to-plant styrene-butadiene-styrene block copolymer components on bitumen modification. Polymers 2019, 11, 140. [CrossRef] [PubMed]

4. Nare, K.; Hlangothi, S.P. Thermorheological evaluation of antiaging behavior of four antioxidants in 70/100 bitumen. J. Mater. Civ. Eng. 2019, 31, 04019034. [CrossRef]

5. Poulikakos, L.D.; Wang, D.; Porot, L.; Hofko, B. Impact of asphalt aging temperature on chemo-mechanics. RSC Adv. 2019, 9, 11602-11613. [CrossRef]

6. Yu, K.; Wang, Y.; Yu, J.; Xu, S. A strain-hardening cementitious composites with the tensile capacity up to $8 \%$. Constr. Build. Mater. 2017, 137, 410-419. [CrossRef]

7. Yu, X.; Zaumanis, M.; Dos Santos, S.; Poulikakos, L.D. Rheological, microscopic, and chemical characterization of the rejuvenating effect on asphalt binders. Fuel 2014, 135, 162-171. [CrossRef]

8. Guindon, L. The Effects of minerals on heavy-oil and bitumen chemistry when recovered by steam-assisted methods. J. Can. Petrol. Technol. 2015, 54, 15-17. [CrossRef]

9. Zhang, W.; Jia, Z.; Wang, F. Effect and prediction of aromatic oil on swelling degree of direct-to-plant SBS modifier in bitumen. Petrol. Sci. Technol. 2019, 37, 1033-1040. [CrossRef]

10. Zhang, W.; Ding, L.; Jia, Z. Design of SBS-modified bitumen stabilizer powder based on the vulcanization mechanism. Appl. Sci. 2018, 8, 457. [CrossRef] 
11. Kumbargeri, Y.S.; Biligiri, K.P. Rational performance indicators to evaluate asphalt materials' aging characteristics. J. Mater. Civil Eng. 2016, 28, 04016157. [CrossRef]

12. Kayukova, G.P.; Vakhin, A.V.; Mikhailova, A.N.; Petrov, S.M.; Sitnov, S.A. Road bitumen's based on the vacuum residue of heavy oil and natural asphaltite: Part I-chemical composition. Petrol. Sci. Technol. 2017, 35, 1680-1686. [CrossRef]

13. Abdullin, A.I.; Idrisov, M.R.; Emelyanycheva, E. Improvement of thermal-oxidative stability of petroleum bitumen using "overoxidation-dilution" technology and introduction of antioxidant additives. Petrol. Sci. Technol. 2017, 35, 1859-1865. [CrossRef]

14. Zhang, W.; Zhang, Y.X.; Jia, Z.; Wang, F.; Ding, L. Test method and material design of asphalt mixture with the function of photocatalytic decomposition of automobile exhaust. Constr. Build. Mater. 2019, 215, 298-309. [CrossRef]

15. Zhang, W.; Shi, J.; Jia, Z. The UV anti-aging performance of TPS modified bitumen. Petrol. Sci. Technol. 2018, 36, 1164-1169. [CrossRef]

16. Hung, A.M.; Fini, E.H. Absorption spectroscopy to determine the extent and mechanisms of aging in bitumen and asphaltenes. Fuel 2019, 242, 408-415. [CrossRef]

17. Zhang, H.L.; Yu, J.Y.; Feng, Z.G.; Xue, L.H.; Wu, S.P. Effect of aging on the morphology of bitumen by atomic force microscopy. J. Microsc. 2012, 246, 11-19. [CrossRef] [PubMed]

18. Wu, S.P.; Pang, L.; Mo, L.T.; Chen, Y.C.; Zhu, G.J. Influence of aging on the evolution of structure, morphology and rheology of base and SBS modified bitumen. Constr. Build. Mater. 2019, 23, 1005-1010. [CrossRef]

19. Rashid, F.; Hossain, Z.; Bhasin, A. Nanomechanistic properties of reclaimed asphalt pavement modified asphalt binders using an atomic force microscope. Int. J. Pavement Eng. 2019, 20, 357-365. [CrossRef]

20. Li, B.; Cui, Y.; Liu, X.; Li, H.; Li, X. Effect of material composition on nano-adhesive characteristics of styrene-butadiene-styrene copolymer-modified bitumen using atomic force microscope technology. Int. J. Adhes. Adhes. 2019, 89, 168-173. [CrossRef]

21. Kim, H.H.; Mazumder, M.; Torres, A.; Lee, S.J.; Lee, M.S. Characterization of CRM binders with wax additives using an atomic force microscopy (AFM) and an optical microscopy. Adv. Civil Eng. Mater. 2017, 6, 504-525. [CrossRef]

22. Nazzal, M.D.; Abu-Qtaish, L.; Kaya, S.; Powers, D. Using atomic force microscopy to evaluate the nanostructure and nanomechanics of warm mix asphalt. J. Mater. Civil Eng. 2015, 27, 04015005. [CrossRef]

23. Loeber, L.; Sutton, O.; Morel, J.; Valleton, J.M.; Muller, G. New direct observations of asphalts and asphalt binders by scanning electron microscopy and atomic force microscopy. J. Microsc. 1996, 182, 32-39. [CrossRef]

24. Li, B.; Yang, J.; Chen, Z.; Li, H. Microstructure morphologies of asphalt binders using atomic force microscopy. J. Wuhan Univ. Tech. Mater. Sci. Ed. 2016, 31, 1261-1266. [CrossRef]

25. Dehouche, N.; Kaci, M.; Mouillet, V. The effects of mixing rate on morphology and physical properties of bitumen/organo-modified montmorillonite nanocomposites. Constr. Build. Mater. 2016, 114, 76-86. [CrossRef]

26. Du, P.F.; Ke, N.X.; Zhang, H.L. Effect of nano-zinc oxide on the morphology and ultraviolet aging properties of various bitumens. Petrol. Sci. Technol. 2015, 33, 1110-1117. [CrossRef]

27. Hofko, B.; Eberhardsteiner, L.; Füssl, J.; Grothe, H.; Handle, F.; Hospodka, M.; Grossegger, D.; Nahar, S.N.; Schmets, A.J.M.; Scarpas, A. Impact of maltene and asphaltene fraction on mechanical behavior and microstructure of bitumen. Mater. Struct. 2016, 49, 829-841. [CrossRef]

28. Hung, A.M.; Fini, E.H. AFM study of asphalt binder "bee" structures: Origin, mechanical fracture, topological evolution, and experimental artifacts. RSC Adv. 2015, 5, 96972-96982. [CrossRef]

29. Dai, Z.; Shen, J.; Shi, P. Influence of SBS modification on the asphalt aging based on nano-sized topography and rheological properties. Acta Petrol. Sin. 2017, 33, 578-587. [CrossRef]

30. Masson, J.F.; Leblond, V.; Margeson, J. Bitumen morphologies by phase-detection atomic force microscopy. J. Microsc. 2006, 221, 17-29. [CrossRef]

31. Mansourkhaki, A.; Ameri, M.; Daryaee, D. Application of different modifiers for improvement of chemical characterization and physical-rheological parameters of reclaimed asphalt binder. Constr. Build. Mater. 2019, 203, 83-94. [CrossRef]

32. RIOH. Standard Test Methods of Bitumen and Bituminous Mixtures for Highway Engineering (JTG E20-2011) Beijing; China Communications Press: Beijing, China, 2011. 
33. Lu, H.; Ye, F.; Yuan, J.; Yin, W. Properties comparison and mechanism analysis of naphthenic oil/SBS and nano-MMT/SBS modified asphalt. Constr. Build. Mater. 2018, 187, 1147-1157. [CrossRef]

34. Filippi, S.; Cappello, M.; Merce, M.; Polacco, G. Effect of nanoadditives on bitumen aging resistance: a critical review. J. Nanomater. 2018, 2018, 2469307. [CrossRef]

35. Blom, J.; Soenen, H.; Katsiki, A.; Van den Brande, N.; Rahier, H.; Van den Bergh, W. Investigation of the bulk and surface microstructure of bitumen by atomic force microscopy. Constr. Build. Mater. 2018, 177, 158-169. [CrossRef]

36. Teltayev, B.B.; Rossi, C.O.; Ashimova, S.Z. Composition and rheological characteristics of bitumen in short-term and long-term aging. Mag. Civil Eng. 2018, 81, 93-101. [CrossRef]

37. Tarsi, G.; Varveri, A.; Lantieri, C.; Scarpas, A.; Sangiorgi, C. Effects of different aging methods on chemical and rheological properties of bitumen. J. Mater. Civil Eng. 2018, 30, 04018009. [CrossRef]

38. Hofko, B.; Cannone Falchetto, A.; Grenfell, J.; Huber, L.; Lu, X.; Porot, L.; Poulikakos, L.D.; You, Z. Effect of short-term ageing temperature on bitumen properties. Road Mater. Pavement Des. 2017, 18, 108-117. [CrossRef]

39. Loise, V.; Vuono, D.; Policicchio, A.; Teltayev, B.; Gnisci, A.; Messina, G.; Rossi, C.O. The effect of multiwalled carbon nanotubes on the rheological behaviour of bitumen. Colloids Surf. A Physicochem. Eng. Asp. 2019, 566, 113-119. [CrossRef]

40. Calandra, P.; Caputo, P.; De Santo, M.P.; Todaro, L.; Liveri, V.T.; Rossi, C.O. Effect of additives on the structural organization of asphaltene aggregates in bitumen. Constr. Build. Mater. 2019, 199, 288-297. [CrossRef]

41. Lin, Y.C.; Wang, H.A.; Hsieh, Y.F. Image matting through a Web browser. Multimed. Tools Appl. 2012, 61, 551-570. [CrossRef]

42. Han, B.; Lu, G.Y.; Zhu, Z.Q.; Guo, Y.J.; Zhao, Y.W. Microstructure features of powdery coal-bearing soil based on the digital image measurement technology and fractal theory. Geotech. Geol. Eng. 2019, 37, 1357-1371. [CrossRef]

43. Vlahović, M.M.; Savić, M.M.; Martinović, S.P.; Boljanac, T.Đ.; Volkov-Husović, T.D. Use of image analysis for durability testing of sulfur concrete and Portland cement concrete. Mater. Des. 2012, 34, 346-354. [CrossRef]

44. Wang, M.; Liu, L.P.; Luo, D. Analysis of nanoscale evolution features of microstructure of asphalt. China J. Highw. Transp. 2017, 30, 10-16. [CrossRef]

45. Yang, J.; Gong, M.; Pauli, T.; Wei, J.; Wang, X. Study on micro-structures of asphalt by using atomic force microscopy. Acta Petrolei. Sin. 2015, 31, 959-965.

46. Wang, P.; Dong, Z.J.; Tan, Y.Q.; Liu, Z.Y. Investigating the interactions of the saturate, aromatic, resin, and asphaltene four fractions in asphalt binders by molecular simulations. Energy Fuels 2015, 29, 112-121. [CrossRef]

47. Li, Y.; Wu, S.; Liu, Q.; Xie, J.; Li, H.; Dai, Y.; Li, C.; Nie, S.; Song, W. Aging effects of ultraviolet lights with same dominant wavelength and different wavelength ranges on a hydrocarbon-based polymer (asphalt). Polymer Testing 2019, 75, 64-75. [CrossRef]

48. Kim, H.H.; Mazumder, M.; Lee, S.J. Micromorphology and rheology of warm binders depending on aging. J. Mater. Civil Eng. 2017, 29, 04017226. [CrossRef]

49. Hou, Y.; Ji, X.; Su, X. Mechanical properties and strength criteria of cement-stabilised recycled concrete aggregate. Int. J. Pavement Eng. 2019, 20, 339-348. [CrossRef]

(C) 2019 by the authors. Licensee MDPI, Basel, Switzerland. This article is an open access article distributed under the terms and conditions of the Creative Commons Attribution (CC BY) license (http://creativecommons.org/licenses/by/4.0/). 